\title{
Densidade, estrutura e distribuição espacial de castanheira-do-brasil (Bertholletia excelsa H. \& B.) em dois platôs de floresta ombrófila densa na Amazônia setentrional brasileira \\ Density, structure and spatial distribution of Brazilnut trees (Bertholletia excelsa H. \& B.) on two plateaus of moist evergreen forest in the northern Brazilian Amazon
}

Rafael de Paiva Salomão'

Resumo: A castanheira (Bertholletia excelsa H. \& B. - Lecythidaceae) é uma espécie nativa da Amazônia que tem por habitat as terras não inundáveis (terra firme). $O$ fruto da castanheira é o produto florestal não-madeireiro (PFNM) mais conhecido e solidamente estabelecido nos mercados doméstico e de exportação há mais de um século, constituindose na única colheita de sementes comercializada internacionalmente que é feita exclusivamente em florestas tropicais primárias. Este trabalho objetiva avaliar a abundância, a distribuição espacial, a estrutura em diâmetro, altura e idade de castanheiras e sua distribuição espacial nos castanhais existentes na floresta pluvial tropical densa em dois platôs na Amazônia setentrional brasileira. Os locais de estudos, denominados platô Almeidas e Aviso, abrangem uma área de, respectivamente, 763 ha e 1.365 ha, onde foram feitos dois inventários, com 100\% de intensidade, de todas as árvores de $B$. excelsa com DAP $\geq 10 \mathrm{~cm}$, sendo registradas, respectivamente, 1.140 e sete árvores, ou seja, densidade de 1,5 árvore/ha e 0,005 árvore/ha. O percentual de árvores jovens (DAP $\leq 60 \mathrm{~cm}$ ) registrado nos dois platôs estudados é inversamente proporcional à abundância, ou seja, 1,21\% (19 árvores) no castanhal de maior densidade (Almeidas) e $71,4 \%$ (cinco árvores) no de menor, o que sugere uma colonização recente no platô Aviso. O maior número de árvores $(64,1 \%$ do total) ocorreu no intervalo de $90-160 \mathrm{~cm}$ de diâmetro, entre 200-300 cm foram registradas 78 árvores (6,8\% do total). Atualmente, é relativamente raro encontrar castanheiras com diâmetros acima de $300 \mathrm{~cm}$; os nove indivíduos acima deste limite, registrados no platô Almeidas, muito provavelmente têm algumas centenas de anos. A abundância de castanheiras no platô Almeidas e Aviso é uma questão intrigante e difícil de desvendar. Existe a possibilidade de se considerar a origem antrópica dos castanhais do platô Almeidas, que poderá ou não ser confirmada por meio de futuros estudos.

Palavras-chave: Estrutura florestal. Lecythidaceae. Castanheira-do-brasil. Produto florestal não madeireiro.

Abstract: The Brazilnut tree (Bertholletia excelsa H. \& B. - Lecythidaceae) is native to the Amazon River basin where it is found in non-flooding, upland forests. The nut is the best known non-timber forest product from the Amazon and has been firmly established in overseas trade for over a century as the only seed in international commerce that is collected solely from primary tropical forest. This study evaluates Brazilnut tree abundance, spatial distribution, diameter, height, and age in dense tropical rain forests on two plateaus in northern Brazilian Amazonia. The study sites, termed the Almeidas and Aviso plateaus, include forested areas of 763 and 1,365 ha, respectively, where forest inventories were made including all Brazilnut trees with $\mathrm{dbh} \geq 10 \mathrm{~cm}$. The two areas had 1,140 and seven Brazilnut trees, respectively, yielding densities of 1.5 trees/ha and 0.005 trees/ha. Percentages of young trees $(\mathrm{dbh} \leq 60 \mathrm{~cm})$ on the two plateaus were inversely related to Brazilnut tree abundense, that is $1.21 \%$ (19 trees) in higher density (Almeidas) and $71.4 \%$ (five trees) in the lower (Aviso), suggesting a recent colonization in Aviso plateau. The largest number of trees (64.1\% of total) occurred within $90-160 \mathrm{~cm}$ of dbh, and 78 trees were recorded between $200-300 \mathrm{~cm}$ (6.8\% in total). Today, it is rare to find Brazilnut trees with diameters up to $300 \mathrm{~cm}$; the nine individuals recorded above this limit on the Almeidas plateau probably have several hundred years. The abundance of Brazilnut in Almeidas and Aviso plateaus is an intriguing question and difficult to unravel. There is the possibility to consider the anthropic origin of the Brazilnut trees in Almeidas plateau, which could be confirmed by further studies.

Keywords: Forest structure. Lecythidaceae. Brazilnut. Non-timber forest product.

\footnotetext{
Museu Paraense Emílio Goeldi. Coordenação de Botânica. Belém, Pará, Brasil (salomao@museu-goeldi.br).
}

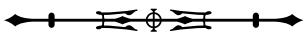




\section{INTRODUÇÃO}

A castanheira (Bertholletia excelsa H. \& B.) é uma espécie nativa da Amazônia que tem por habitat as terras não inundáveis (terra firme). É uma árvore cujo fruto apresenta alto valor alimentar e com expressão no comércio internacional, constituindo-se em um dos principais produtos extrativistas da pauta de exportação da Amazônia, principalmente do estado do Pará.

$O$ fruto da castanheira é o produto florestal nãomadeireiro (PFNM) mais conhecido e solidamente estabelecido nos mercados doméstico e de exportação há mais de um século, constituindo-se na única colheita de sementes comercializada internacionalmente que é feita exclusivamente em florestas tropicais primárias (Peters, 1994; Clay, 1997; Peres et al., 2003). A coleta e o processamento das castanhas sustentam mais da metade da população rural em muitas partes da Amazônia e é frequentemente festejada como sendo um exemplo de indústria sustentável de PFNM, pois sustenta as inúmeras comunidades e suas economias regionais, ao mesmo tempo em que promove a conservação da floresta (Allegretti, 1994; Clay, 1997; Peres et al., 2003; Salomão et al., 2006). Somente na Amazônia brasileira, mais de 30.555 toneladas de amêndoas de castanha foram coletadas anualmente, cuja venda alcançou mais de US\$23,3 milhões (IBGE, 2005).

As castanheiras atingem maturidade reprodutiva bem cedo (indivíduos de somente 14 anos podem produzir flores e frutos quando em condições ótimas de iluminação). Considerando o seu porte e a fecundidade, esta espécie continua aumentando a produção de ouriços e, consequentemente, de amêndoas, junto com o tamanho, até um determinado ponto (Zuidema \& Boot, 2002). Peres et al. (2003) analisaram as ameaças demográficas à sustentabilidade da exploração da castanha em 21 populações espalhadas pela Amazônia brasileira, boliviana e peruana, mostrando que o nível de coleta é o determinante principal da estrutura de tamanho das populações.

Encontrada em agrupamentos mais ou menos extensos (denominados castanhais), está sempre associada a outras espécies florestais de grande porte. Sua área de ocorrência vai desde o extremo sul do Escudo das Guianas até $\mathrm{o}$ alto Beni ( $14^{\circ}$ latitude sul); seu limite leste encontrase a noroeste do Maranhão, na bacia do rio Gurupi (R. L. Fróes apud Ducke \& Black, 1954). Em casos excepcionais, a castanheira pode chegar a 50 metros de altura e seu tronco não ramificado, quando em floresta primária, pode medir vários metros de diâmetro; fato observado também para a samaúma (Ceiba pentandra (L.) Gaertn.) e o piquiá (Caryocar villosum (Aubl.) Pers.), sempre com menores diâmetros (Ducke \& Black, 1954).

Pereira \& Costa (1981) compilaram vários estudos sobre $B$. excelsa em um banco bibliográfico. Almeida (1966) analisou, principalmente, os vários aspectos ligados desde a coleta dos frutos na mata até a exportação. Pandolfo (1960) sugeriu medidas racionais que deveriam ser tomadas no beneficiamento da castanha. Tupiassu \& Oliveira (1967) forneceram um diagnóstico socioeconômico sobre a castanha. Muller et al. (1980) revelaram resultados sobre germinação, enxertia, biologia floral e polinização da castanheira. $\bigcirc$ papel econômico e, sobretudo, social dos castanhais da região de Marabá foram discutidos e interpretados por Kitamura \& Muller (1984), que propuseram algumas medidas para preservação em detrimento da depredação. Moritz (1984) estudou detalhadamente os fatores biológicos da floração e frutificação da espécie. Bentes et al. (1988) documentaram a destruição acelerada dos castanhais do Tocantins. Informações esparsas sobre a estrutura e a fitossociologia de castanheiras são encontradas nos trabalhos de Pires $(1973,1976)$, SUDAM (1974), Projeto RADAM (1974a, b, 1975, 1976), Dantas \& Muller (1980), Carvalho (1981), Campbell et al. (1986), Absy et al. (1986/87), Silva et al. (1987) e Salomão (1991).

Este trabalho objetiva avaliar a abundância, a estrutura em diâmetro, altura e idade das árvores de castanheiras e sua distribuição espacial nos castanhais existentes na floresta ombrófila densa submontana em dois platôs na Amazônia setentrional brasileira. 


\section{MATERIAL E MÉTODOS}

\section{ÁREA DE ESTUDO}

Os locais de estudo foram os platôs (grandes extensões de terrenos planos ou pouco ondulados, elevados - 170 $m$ de altitude, cortados por vales neles encaixados)

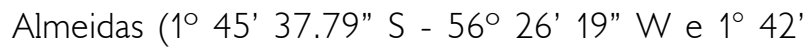
$\left.54.86^{\prime \prime} \mathrm{S}-56^{\circ} 22^{\prime} \mathrm{W}\right)$ e Aviso (14 $47^{\prime} 02.56^{\prime \prime} \mathrm{S}-56^{\circ}$ 31' 49" W e $1^{\circ} 43^{\prime} 40.55^{\prime \prime}$ S - 56 26' 58" W), que abrangem uma área de aproximadamente 763 ha e 1.365 ha, respectivamente, localizados na Floresta Nacional Saracá-Taquera/ICMBio, onde a Mineração Rio do Norte S.A.- MRN desenvolve um projeto mínero- industrial de bauxita, no distrito de Porto Trombetas, município de Oriximiná, estado do Pará (Figura 1).

Na bacia amazônica, os depósitos de bauxita são associados à série Barreiras do Terciário, constituídos de arenitos, siltitos e, ocasionalmente, conglomerados. As lateritas são encontradas no topo dos platôs, fortemente dissecados pela erosão, remanescentes do peneplano Terciário, que se estendem ao longo do lado nordeste do rio Amazonas, desde as vizinhanças de Oriximiná até Jardilândia, no rio Jari (Lapa, 2000). Esses platôs são bem definidos, têm os topos planos, achatados, com altitudes entre $150 \mathrm{~m}$ a $200 \mathrm{~m}$ em relação ao nível do mar.

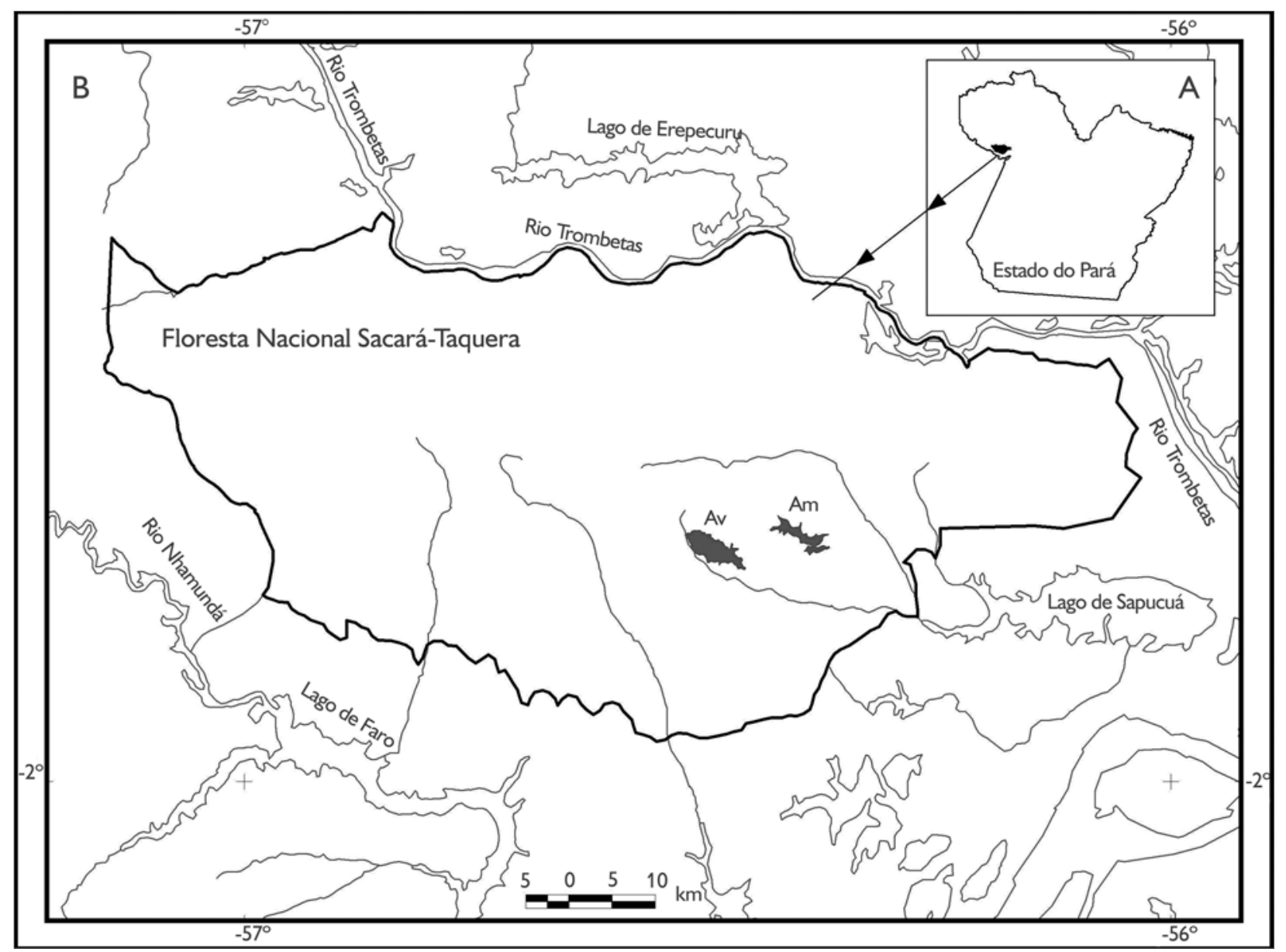

Figura 1. Localização da unidade de conservação no estado do Pará (A), denominada Flona Sacará-Taquera/ICMBio (B), onde se observa a conformação espacial dos platôs Aviso (Av) e Almeidas (Am) com áreas de, respectivamente, 1.365 ha e 763 ha.

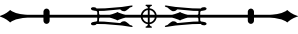


A área está inserida na região da floresta ombrófila densa, sub-região dos baixos platôs da Amazônia, domínio da floresta densa submontana, cuja fitofisionomia refere-se à floresta localizada, principalmente nos platôs terciários e terraços antigos e recentes, apresentando-se em dois estratos distintos: um emergente e outro uniforme (Projeto Radam, 1976). As principais espécies que caracterizam o estrato emergente são: Dinizia excelsa Ducke (angelimpedra), Bertholletia excelsa (castanheira) e Cedrelinga cateniformis (Ducke) Ducke (cedrorana). O estrato uniforme é caracterizado por Manilkara spp. (maçarandubas), Protium spp. (breus) e Pouteria spp. (abius).

O clima da região é o AF1, que apresenta precipitação pluviométrica média anual variando entre 2.500 - 3.000 mm, com médias anuais de temperatura, precipitação pluviométrica, umidade relativa e insolação de, respectivamente, $26^{\circ} \mathrm{C}, 2.197 \mathrm{~mm}, 81 \%$ e 2.026 horas (Inemet, 2006).

\section{PROCEDIMENTOS DE CAMPO}

O platô Almeidas possui uma conformação que permite visualizar a existência de três blocos distintos. Em cada bloco, foi aberta, pela equipe de topografia, uma picada na direção leste-oeste, balizada com estacas de madeira a cada 50 m. Analogamente, na direção norte-sul, perpendicularmente ao eixo leste-oeste, foi aberta outra picada com a mesma distância entre balizas. A partir desses eixos ortogonais, foram feitas picadas a cada $50 \mathrm{~m}$, formando transectos que delimitavam as parcelas (unidades amostrais) de $50 \mathrm{~m} \times 50 \mathrm{~m}$ (0,25 ha), constituindo uma grade de quadrados com lados de $50 \mathrm{~m}$ (Figura 2). O platô Aviso possui uma conformação relativamente simétrica que permitiu a caracterização de cinco eixos paralelos nas direções leste-oeste para operacionalização dos trabalhos de campo. A partir desses eixos, foram feitas picadas que caracterizaram as parcelas, com dimensões de $50 \mathrm{~m} \times 50$ m (0,25 ha), para realização dos trabalhos das equipes de inventário (Figura 3). Estes platôs estão distantes por cerca de $10 \mathrm{~km}$.
No inventário florestal, com intensidade de 100\% de amostragem, todas as castanheiras com DAP $\geq 10 \mathrm{~cm}$ foram registradas, sendo medidos o DAP (diâmetro a 1,30 $m$ do solo) e estimadas as alturas do fuste e da copa por meio de uma vara de $5 \mathrm{~m}$ marcada a cada metro.

Para verificar o padrão de distribuição espacial dos indivíduos das populações de castanheiras, foi usado o índice de agregação de Payandeh (1970) $P$, expresso pelo quociente entre a variância do número de castanheiras por parcela e a média do número total de castanheiras do platô. Valores de $P$ superiores a 1,5 indicam distribuição agregada ou agrupada; $P$ variando de 1,0 a 1,5 corresponde à tendência ao agrupamento e $P$ inferior a 1,0 indica distribuição aleatória ou não-agrupada.

\section{RESULTADOS E DISCUSSÃO}

Os trabalhos de campo do platô Almeidas (763 ha) envolveram 66 auxiliares de campo durante 32 dias ininterruptos de atividades. Foram abertos, aproximadamente, $305 \mathrm{~km}$ de picadas no interior da floresta densa. Em todo o platô, foram delimitadas 3.052 parcelas de 0,25 ha, sendo que em 815 destas (26,7\% do total) foram registradas 1.140 castanheiras, equivalente a uma abundância média de 1,5 árvore/ha.

No platô Aviso (1.365 ha), os trabalhos de campo envolveram o mesmo número de auxiliares durante 58 dias ininterruptos de atividades. Foram abertos, aproximadamente, $546 \mathrm{~km}$ de picadas e delimitadas 5.460 parcelas de 0,25 ha, onde foi registrado um total de apenas sete castanheiras.

\section{ABUNDÂNCIA}

Considerando apenas as parcelas com ocorrência de castanheira no platô Almeidas, a abundância variou de 1 a 6 árvores/parcela de 0,25 ha (Tabela 1); em termos de hectare, observou-se uma amplitude de 1 a 12 árvores/ ha. Este valor máximo pode ser deduzido pela análise das parcelas que apresentaram 4 árvores/0,25 ha e as possíveis combinações com suas vizinhas e respectivas abundâncias; 


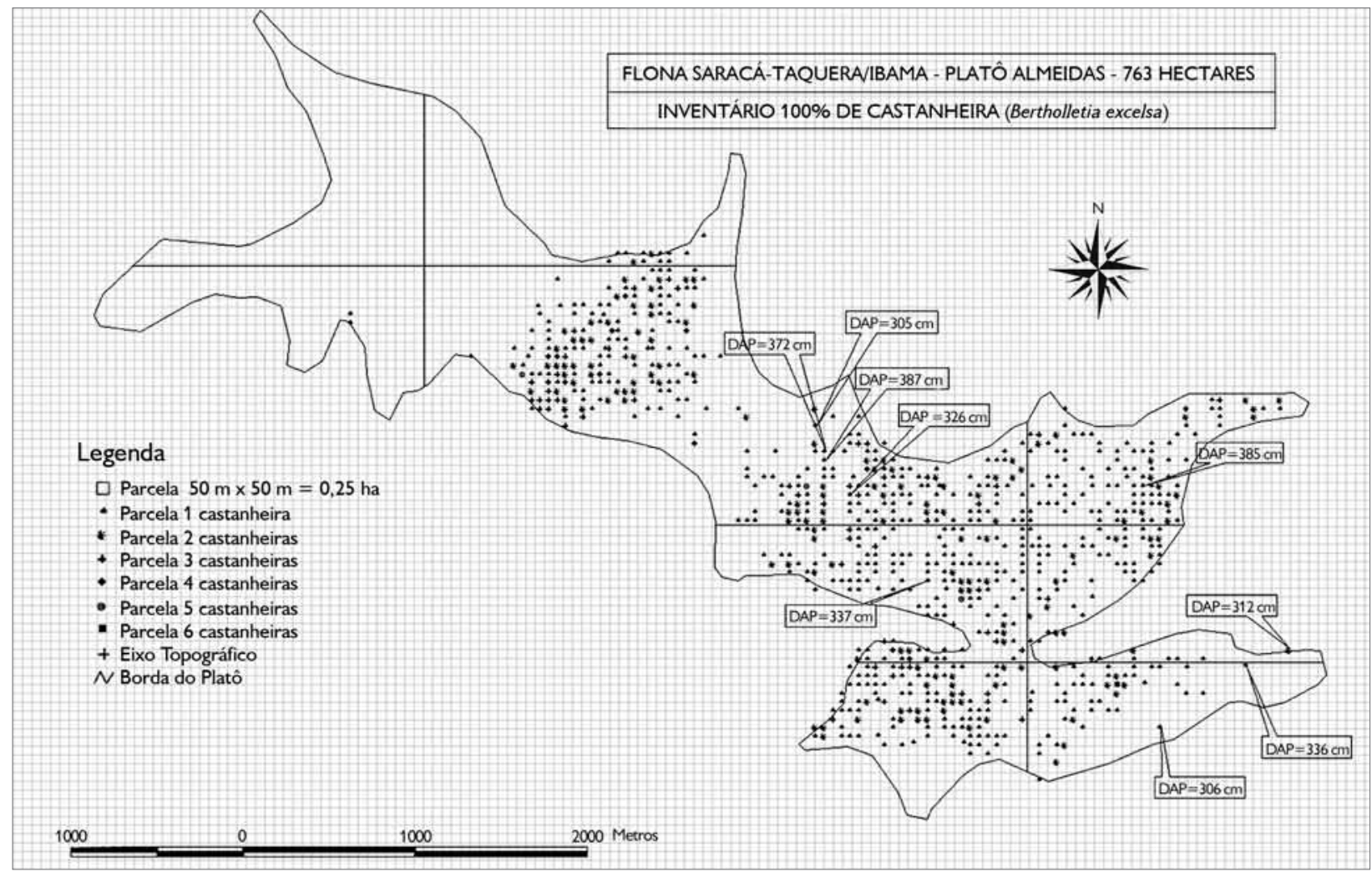

Figura 2. Distribuição espacial das 1.140 castanheiras registradas no platô Almeidas, destacando-se a localização das nove árvores com DAP > 300 cm; Flona Saracá-Taquera/ICMBio, Porto Trombetas, Oriximiná, Pará. Fonte: Autor

várias outras estimativas de 11 árvores/ha podem também ser analogamente deduzidas, entretanto, apenas uma combinação possível aponta para aquele valor máximo (Figura 2). Estes valores são altos quando comparados com as médias citadas na literatura especializada: Pires (1973, 1976), SUDAM (1974), Projeto RADAM (1974a, b, 1975, 1976), Dantas \& Muller (1980), Carvalho (1981), Campbell et al. (1986), Absy et al. (1986/87), Silva et al. (1987) e Salomão (1991). Analogamente, no platô Aviso, as sete castanheiras registradas (Tabela 1) geraram uma abundância média de 0,001275 árvore/parcela de 0,25 ha ou 0,0051 árvore/ha.

Na rodovia Transamazônica, entre os municípios de Itaituba, Pará, e Altamira, Pará, em 1,5 ha de floresta densa de terra firme, Dantas \& Muller (1980) registraram três árvores com DAP $\geq 9,5 \mathrm{~cm}$ (média de 2,0 árvores/ ha). Na Floresta Nacional do Tapajós/ICMBio, à margem da rodovia Cuiabá-Santarém, em 35 ha de floresta densa, Carvalho (1981) registrou 24 árvores com DAP $\geq 15 \mathrm{~cm}$, média de 0,7 árvore/ha. Em 3 ha de floresta de terra firme no médio Xingu, Campbel et al. (1986) encontraram quatro castanheiras com DAP $\geq 10 \mathrm{~cm}$, média de 1,3 árvore/ha. Os maciços de B. excelsa, na Amazônia, formam inúmeros castanhais com alta densidade de plantas por unidade de área, sobretudo na região de Marabá, onde Salomão (1991) registrou, em oito parcelas de 1 ha cada, uma média de 3,6 castanheiras/ha (DAP $\geq 10 \mathrm{~cm}$ ). Segundo Ducke \& Black (1954), as florestas das terras altas que acompanham o médio Tocantins apresentam alta abundância de castanheiras.

Os dados relativos à densidade de castanheira, apresentados no relatório 'Levantamentos florestais realizados

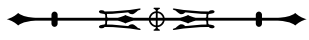




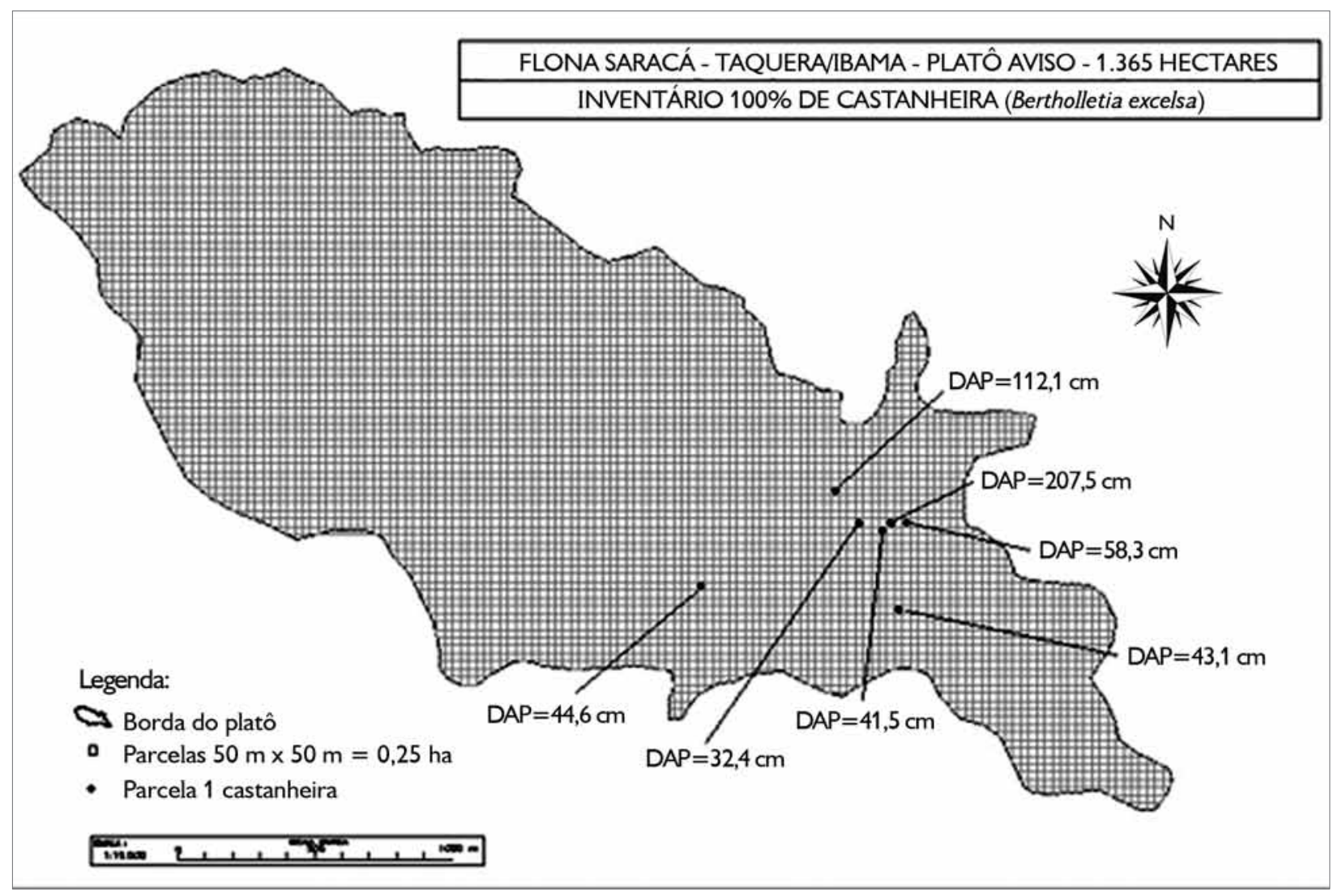

Figura 3. Distribuição espacial das sete castanheiras registradas no platô Aviso; Flona Saracá-Taquera/ICMBio, Porto Trombetas, Oriximiná, Pará.

pela missão FAO na Amazônia (1956 - 1961)', abrangem uma vasta área da Amazônia, todavia, a missão efetuou levantamentos apenas nas regiões entre os rios da margem direita do Amazonas, e como o rio Trombetas, que banha a Flona em questão, estáà esquerda, foi excluído (Salomão, 1991).

O Projeto RADAM (1974a, b) estimou para as subregiões do Araguaia, da Serra dos Carajás e do médio XinguIriri uma média de 1,5 árvore/ha (DAP $\geq 31,8 \mathrm{~cm}$ ) e de 6 árvores/ha para a superfície arrasada do Pará-Amapá. Uma deficiência observada na metodologia dos levantamentos do RADAM em relação ao Pará refere-se aos procedimentos metodológicos adotados em dois relatórios: Folha SB.21 Tapajós (Projeto Radam, 1975) e Folha SA.21 Santarém (Projeto Radam, 1976), que, diferentemente dos outros dois relatórios que complementam o recobrimento da vegetação do estado (Folha SB.22 Araguaia e parte da Folha SC.22
Tocantins (Projeto Radam, 1974a) e Folha SA.22 Belém (Projeto Radam, 1974b), não apresentaram estimativas da espécie por 'efeito de dispositivo legal', ou seja, entendeuse que, sendo a castanheira imune de corte por efeito de uma Portaria do Instituto Brasileiro de Desenvolvimento Florestal (IBDF) (atual Ibama), não se deveriam divulgar informações relacionadas à espécie. Também aqueles outros relatórios, quando informaram, procederam de maneira incompleta; esperava-se que pelo menos dados referentes à abundância devessem ser fornecidos (omitindo-se o volume de madeira), visto tratar-se dos frutos da castanheira de um importante recurso florestal da região, com significância na pauta de comercialização interna e externa.

No platô Almeidas, considerando-se apenas aquelas 815 parcelas onde a castanheira ocorreu, totalizando 1.140 indivíduos, foi estimada uma densidade média de 5,6

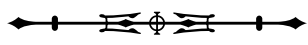


Tabela 1. Número de parcelas com respectiva abundância de castanheiras registradas nos platôs Almeidas e Aviso; Flona Saracá-Taquera/ ICMBio, Porto Trombetas, Oriximiná, Pará.

\begin{tabular}{|c|c|c|c|c|}
\hline \multirow{3}{*}{$N^{\circ}$ de castanheiras } & \multicolumn{2}{|c|}{ Platô Almeidas (763 ha) } & \multicolumn{2}{|c|}{ Platô Aviso (1.365 ha) } \\
\hline & \multicolumn{2}{|c|}{ Parcelas $(0,25$ ha $)$} & \multicolumn{2}{|c|}{ Parcelas $(0,25$ ha $)$} \\
\hline & Quantidade & $\%$ & Quantidade & $\%$ \\
\hline 0 & 2.237 & 73,30 & 5.453 & 99,87 \\
\hline 1 & 584 & 19,13 & 7 & 0,03 \\
\hline 2 & 159 & 5,21 & - & - \\
\hline 3 & 55 & 1,80 & - & - \\
\hline 4 & 13 & 0,43 & - & - \\
\hline 5 & 3 & 0,10 & - & - \\
\hline 6 & 1 & 0,03 & - & - \\
\hline Total com castanheira & 815 & 26,70 & 7 & 0,03 \\
\hline Total geral & 3.052 & 100,00 & 5.460 & 100,00 \\
\hline
\end{tabular}

árvores/ha (DAP $\geq 10 \mathrm{~cm}$ ), excepcionalmente alta em relação a quaisquer outros locais da Amazônia brasileira. Todavia, considerando-se toda a área do platô (3.052 parcelas), a abundância assume valor de 1,49 árvore/ha, semelhante às estimativas citadas pela maioria dos estudos na Amazônia brasileira. Entretanto, deve-se considerar que o extenso castanhal existente no platô Almeidas estava distribuído, efetivamente, em cerca de 3/4 do total da área (Figura 1), representado, majoritariamente, por árvores com diâmetro superior a $130 \mathrm{~cm}$, o que consequentemente permite inferir uma abundância média de 1,99 árvore/ha, enquanto, para todo o platô Aviso, a abundância de 0,0051 castanheira/ha é extremamente baixa.

\section{ESTRUTURA EM DIÂMETRO E ALTURA}

A análise da distribuição diamétrica das castanheiras do platô Almeidas (Figura 4) permite observar que a grande maioria de indivíduos (64,1\%) ocorre entre 90-160 cm de diâmetro. Indivíduos jovens (DAP $\leq 60 \mathrm{~cm}$ ) são raros $(1,2 \%)$ na população. Setenta e oito indivíduos (6,8\%) apresentaram diâmetros entre $200-300 \mathrm{~cm}$, enquanto nove espécimes (0,8\%) apresentaram diâmetros superiores a $300 \mathrm{~cm}$.

Sinteticamente, como observado no platô Almeidas, praticamente $1 / 3$ do total de castanheiras estava abaixo das duas classes de maior abundância (intervalo de 110$130 \mathrm{~cm}$ ) que, juntas, respondem por quase 1/4 do total de árvores; praticamente a metade das castanheiras apresentou diâmetro superior a $130 \mathrm{~cm}$ (Figura 4), destacando-se, entre elas, nove exemplares com mais de $300 \mathrm{~cm}$ de DAP (Figura 5).

No platô Aviso, foram registradas cinco castanheiras no intervalo de $30-60 \mathrm{~cm}$, uma entre $110-120 \mathrm{~cm}$ e a outra entre 200-210 cm (Figura 6). Curiosamente, neste local, o percentual de árvores abaixo de $60 \mathrm{~cm}$ de DAP é superior ao acima deste limite: $71,4 \%$ e $28,6 \%$, respectivamente; tal fato, até então, nunca foi registrado. Este percentual de árvores jovens sugere uma colonização recente neste platô.

Geralmente, os estudos apontam uma ausência de indivíduos de castanheira nas classes inferiores a $60 \mathrm{~cm}$, devido, entre outros fatores, ser esta espécie exigente em relação à luz, o que ocasiona o não desenvolvimento da muda após a germinação da semente em floresta fechada; o pleno desenvolvimento só ocorrerá quando em clareiras naturais, onde a luz atinge o 'piso' da mata. A intensidade de amostragem e o tamanho da amostra são também fatores importantes, conforme demonstrado neste estudo, onde, em todas as menores classes (abaixo de $60 \mathrm{~cm}$ ), foram registrados indivíduos. 


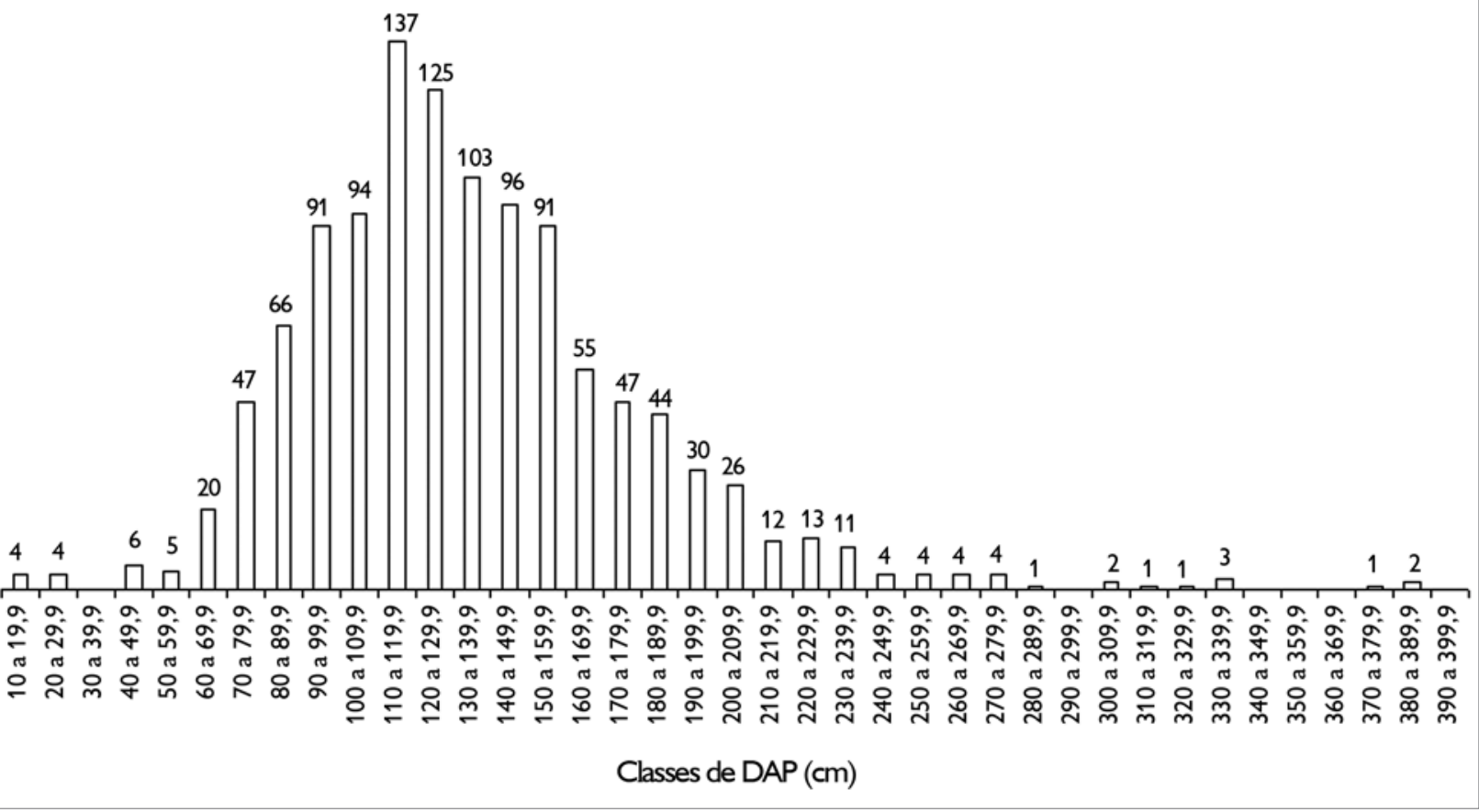

Figura 4. Distribuição do número de castanheiras em classes diamétricas, platô Almeidas (763 ha), Flona Saracá-Taquera/ICMBio, Porto Trombetas, Oriximiná, Pará.

Peres et al. (2003) demonstraram que os níveis atuais de coleta de amêndoas, na Amazônia, têm um impacto importante no recrutamento interno das populações naturais de castanheira, através da análise comparativa de 21 populações espalhadas pela Amazônia brasileira, boliviana e peruana, mostrando que o nível de coleta é o determinante principal da estrutura de tamanho das populações; aquelas populações sujeitas a níveis de coleta altos ou moderados por várias décadas são carentes de jovens com diâmetro menor do que $60 \mathrm{~cm}$; somente as populações cujo histórico mostra coletas leves ou recentes, ou então nenhuma coleta, têm números significativos de árvores jovens (nas 21 populações foi observada uma amplitude de 0,74\% a 52,5\% de indivíduos jovens).

Prosseguindo, alertaram que um modelo de coleta demonstrou que os níveis históricos de exploração dessas amêndoas, ao longo do último século, são de tal monta que o recrutamento de jovens é insuficiente para o sustento das populações em longo prazo e, não havendo um manejo favorável ativo, as populações terminarão por sucumbir por meio de um processo de senescência e colapso demográfico. Corrobora esta afirmativa o fato de que, entre as populações analisadas, duas estavam em reservas extrativistas no Amapá (Reserva ExtrativistaAlto Cajari e Reserva de Desenvolvimento Sustentável Iratapuru), que, sob forte pressão de coleta, apresentaram os menores percentuais de jovens entre todas as demais 19 populações analisadas, respectivamente, 0,74\% e 0,87\% (Peres et al., 2003).

\section{RELAÇÃO ENTRE O DIÂMETRO E A ALTURA}

A curva hipsométrica que relaciona a altura total e o diâmetro (DAP) das árvores mensuradas no platô Almeidas demonstra que praticamente todos os indivíduos, independentemente do tamanho do diâmetro, ficam na mesma faixa de altura, geralmente entre 30-40 m, raramente chegando próximo a 50 m de altura (Figura 7). 


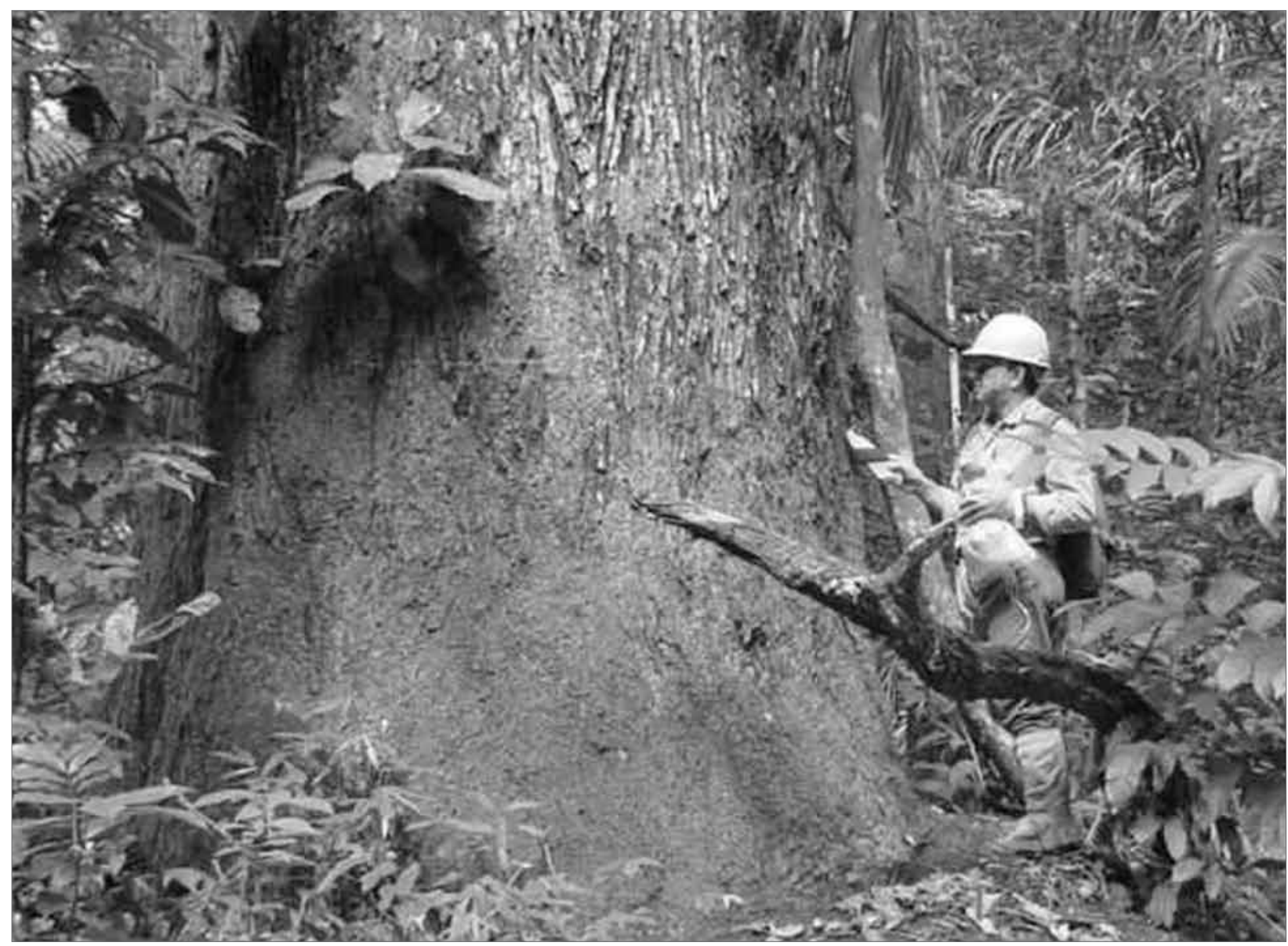

Figura 5. Exemplar de castanheira-do-brasil (Bertholletia excelsa) com diâmetro de $387 \mathrm{~cm}$ e altura total de 48 m amostrado no platô Almeidas, Flona Saracá-Taquera/ICMBio, Porto Trombetas, Oriximiná, Pará. Foto: R. P. Salomão, 2003.

Sendo a espécie eminentemente lucífera, o crescimento em altura é priorizado nos anos iniciais, objetivando alcançar o dossel da floresta no menor espaço de tempo, antes que o mesmo se feche e não permita a chegada de luz na copa para o pleno desenvolvimento da árvore. Uma vez atingido o dossel da floresta, a castanheira assegurará um suprimento de luz suficiente para, a partir daí, incrementar o crescimento em diâmetro (Salomão, 1991).

\section{ESTRUTURA DE IDADE}

Geralmente, aceita-se que as árvores da floresta tropical tenham baixa longevidade, raramente ultrapassando 400 anos. No entanto, Chambers et al. (1998) fizeram datação através do ${ }^{14} \mathrm{C}$ em 20 árvores de 13 espécies emergentes da Amazônia central e, ao contrário de visões convencionais, estimaram idades de até 1.400 anos de um exemplar de Cariniana micrantha Ducke, da mesma família da castanheira. Algumas árvores muito grandes foram estimadas com mais de 1.000 anos (Pires, 1976). As castanheiras são emergentes de vida longa e, em casos extremos, árvores muito velhas provavelmente possam sustentar uma produção de frutos por mais de 800 anos (Peres et al., 2003). Nas matas do rio Jari, no sul do Amapá, ocorreu um exemplar de castanheira com $446 \mathrm{~cm}$ de diâmetro (Pires, 1976). Próximo a Itupiranga, no Pará, foi medido pela equipe de botânica do Museu Paraense Emílio

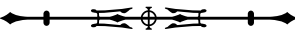




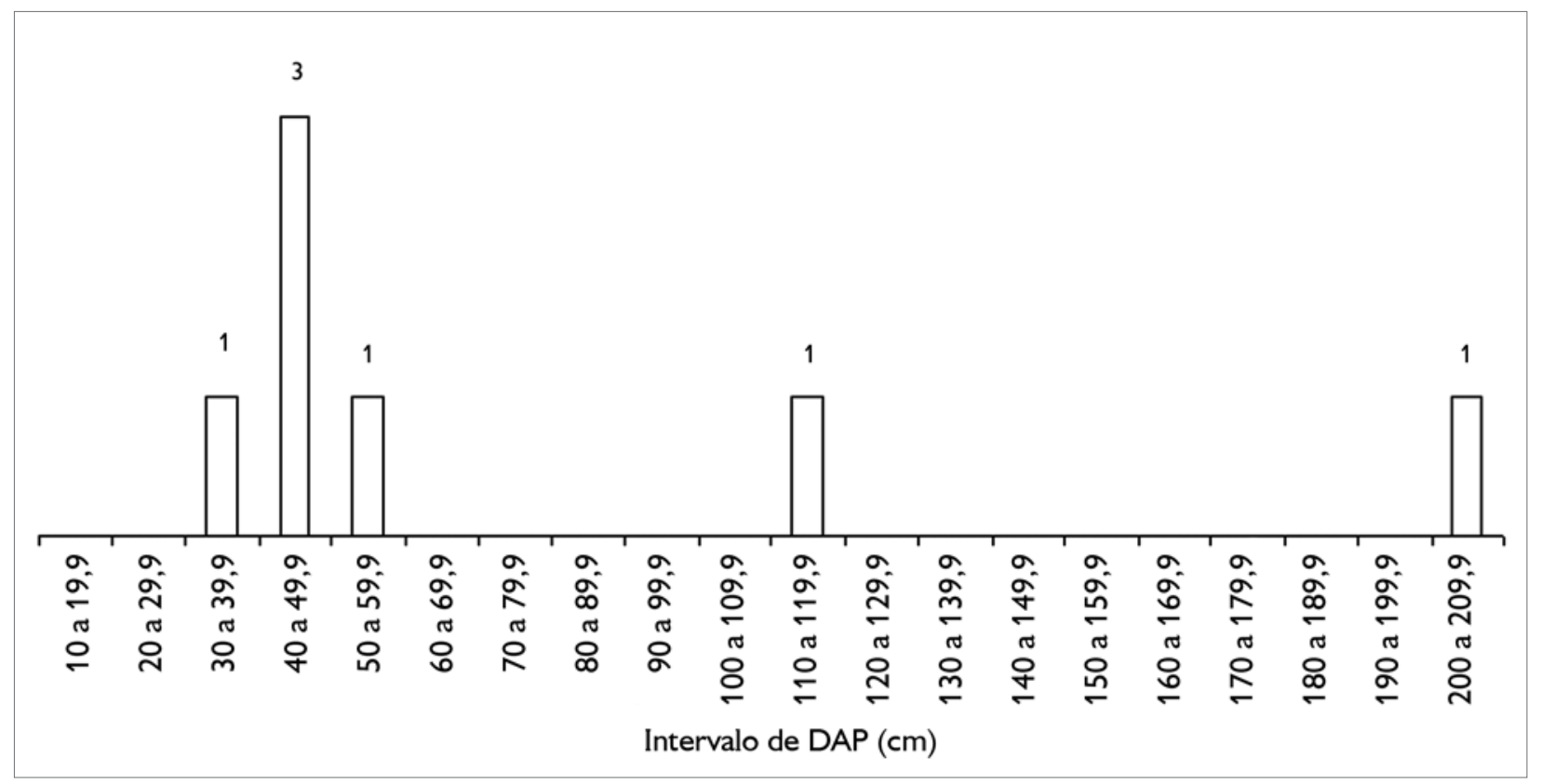

Figura 6. Distribuição das sete castanheiras em classes diamétricas registradas no platô Aviso (1.365 ha); Flona Saracá-Taquera/ICMBio, Porto Trombetas, Oriximiná, Pará.

Goeldi um exemplar, em 1981, com 525 cm de diâmetro; outro indivíduo na Reserva Indígena Kararaô, entres os rios Xingu e Iriri, apresentou $434 \mathrm{~cm}$ de diâmetro e $31 \mathrm{~m}$ de comprimento do tronco (Salomão, 1991).

Camargoet al. (1994), através de datação radiocarbônica, estimaram para uma castanheira de $233 \mathrm{~cm}$ de DAP uma idade de 440 \pm 60 anos, ou seja, incremento médio anual do crescimento diamétrico de $0,53 \mathrm{~cm}^{*}$ ano-1. Extrapolando-se este resultado para aquelas castanheiras citadas anteriormente, chega-se à conclusão de que elas poderiam apresentar uma idade de 842, 991 e 819 anos, respectivamente. Neste estudo, onde os maiores diâmetros mensurados foram de $305,306,312,326,334,337,372$, 385 e 387 cm projetouse, baseando-se naquele incremento, uma idade média de, respectivamente, 576, 578, 589, 616, 631, 636, 702, 727, 731 anos, ou seja, essas castanheiras, muito provavelmente, são anteriores aos colonizadores portugueses que chegaram ao Brasil no ano de 1500.

A análise da estrutura das populações permite inferir que a árvore média de castanheira (árvore teórica), do platô Almeidas, apresentaria $134 \mathrm{~cm}$ de DAP, altura total de 32,3 $\mathrm{m}$, área seccional de $1,6 \mathrm{~m}^{2}$, volume ${ }^{1}$ do tronco igual a 22,3 $\mathrm{m}^{3}$; biomassa aérea ${ }^{2}$ de 18,4 toneladas (peso seco) e uma idade média projetada de 253 anos.

\section{DISTRIBUIÇÃO ESPACIAL}

O índice de Payandeh $(P)$, calculado para avaliar o grau de agregação da espécie através da razão entre a variância do número de castanheiras por parcela e a média do número de árvores, foi de 5,3, indicando que a espécie ocorre agrupada no platô Almeidas. Como estão distribuídas espacialmente as castanheiras nas parcelas de estudo

$\log \mathrm{V}_{c / c}=0,0417316+2,04126 \log \mathrm{DAP}+$ 0,76477 $\log \mathrm{H}$, onde: $\mathrm{V}_{c / c}=$ Volume de madeira com casca; DAP = diâmetro a 1,30 $\mathrm{m}$ do solo com casca; $\mathrm{H}=$ altura do fuste (comercial); $r 2=0,99154 ; \mathrm{F}=5685,3$ (teste $\mathrm{F}$ da regressão) - Queiroz \& Barros (1998).

$2 \mathrm{Y}=0,0899 *\left(\mathrm{DAP} 2 * \mathrm{H}^{*} \mathrm{~S}\right)$ 0,9522 onde: $\mathrm{Y}=$ biomassa aérea viva, peso seco, em kg; DAP = diâmetro a 1,30 m do solo, em cm; H = altura total (fuste + copa), em m; S = Densidade aparente da madeira a 15\% de umidade, em $\mathrm{g}^{*} \mathrm{~cm}^{-3} ; \mathrm{r}^{2}=0,99$ - Brown et al. (1989).

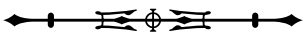




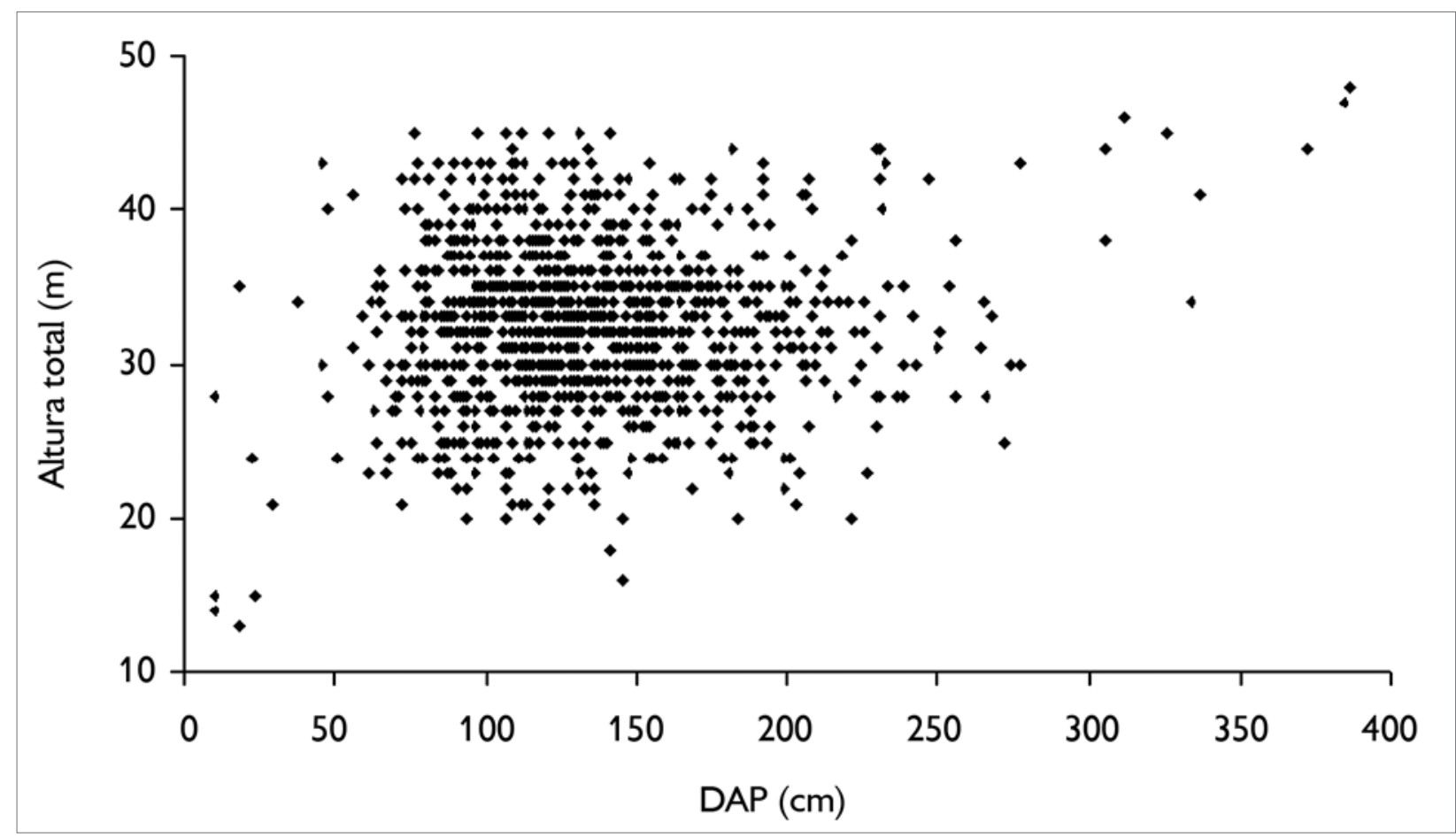

Figura 7. Relação hipsométrica das 1.140 castanheiras amostradas no platô Almeidas; Flona Saracá-Taquera/ICMBio, Porto Trombetas, Oriximiná, Pará.

neste platô e quantos indivíduos existem em cada uma delas? Nas parcelas onde houve ocorrência de castanheira, assinaladas com o respectivo número de árvores (Figura 2), são destacadas aqueles excepcionais nove espécimes que apresentaram diâmetro superior a $300 \mathrm{~cm}$. Três dessas grandes árvores ocorreram isoladas no lado direito do bloco inferior, distantes em um raio de cerca de $200 \mathrm{~m}$ de quaisquer outras árvores da espécie; todas as demais ocorreram no bloco mediano entre vários outros espécimes, sendo que três, diferentemente do bloco inferior, estão muito próximas entre si. Observa-se que o castanhal ocupa, aproximadamente, 3/4 da área total, uma vez que na parte ocidental do bloco superior não ocorreu nenhuma árvore, à exceção de três na borda sul (Figura 2).

Na Flona Saracá-Taquera/ICMBio, onde estão localizados um total de 23 platôs, tem-se uma situação completamente oposta à observada no platô Almeidas no que tange à abundância e distribuição espacial de castanheiras.
Em outros nove platôs inventariados, totalizando uma área de 10.051 ha, B. excelsa ocorreu em apenas três (total de 3.070 ha), com apenas 12 indivíduos amostrados nos inventários, projetando estimativas de 102 castanheiras (limite de erro $\leq 10 \%$ a $95 \%$ probabilidade pelo teste $t$ ), ou seja, abundância de 0,033 árvore/ha (Tabela 2).

Os platôs mais ao sul na Flona, em número de seis, são Aramã e Greig (sem castanheiras amostradas), Bela Cruz e Aviso, virtualmente sem castanheiras (0,02 castanheira/ha e 0,005 castanheira/ha) e os platôs Bacaba (0,3 castanheira/ha) e Almeidas (1,5 castanheira/ha), distantes entre si por cerca de 1,5 km. Estes platôs são os que estão mais próximos de um furo que liga a lagoa do Sapucuá ao rio Amazonas, sendo os platôs Bacaba e Almeidas aqueles que se localizam mais perto das áreas que margeiam a lagoa (Figura 1).

Por que nos demais platôs, afora o Almeidas, a castanheira, quando ocorre, apresenta baixíssima

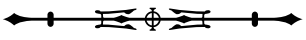


Tabela 2. Abundância de castanheiras em dez platôs da Flona Saracá-Taquera/ICMBio, Porto Trombetas, Oriximiná, Pará.

\begin{tabular}{|c|c|c|c|c|c|c|}
\hline \multirow{2}{*}{ Platô } & \multirow{2}{*}{$\begin{array}{l}\text { Ano do } \\
\text { inventário }\end{array}$} & \multirow{2}{*}{$\begin{array}{l}\text { Área } \\
\text { (ha) }\end{array}$} & \multirow{2}{*}{$\begin{array}{c}\mathrm{N}^{\circ} \text { de } \\
\text { parcelas } \\
(0,25 \mathrm{ha})\end{array}$} & \multicolumn{2}{|c|}{$\mathrm{N}^{\circ}$ de castanheiras $(\mathrm{DAP} \geq 10 \mathrm{~cm})$} & \multirow{2}{*}{$\begin{array}{c}\text { Abundância } \\
\left(n^{\circ} \text { árv/ha) }\right.\end{array}$} \\
\hline & & & & Amostrado & Estimado & \\
\hline Almeidas ${ }^{1}$ & 2002 & 763 & 3.052 & $1.140^{1}$ & - & 1,49 \\
\hline Aviso $^{1}$ & 2002 & 1.365 & 5.460 & $7^{1}$ & - & 0,005 \\
\hline Aramã² & 2006 & 337 & 43 & - & - & - \\
\hline Bacaba $^{2}$ & 2002 & 205 & 54 & 4 & $61^{2}$ & 0,3 \\
\hline Bela Cruz ${ }^{2}$ & 2003 & 1.500 & 179 & 1 & 342 & 0,023 \\
\hline Cipó2 & 2005 & 1.117 & 95 & - & - & - \\
\hline Greig $^{2}$ & 2006 & 143 & 30 & - & - & - \\
\hline Monte Branco 2 & 2006 & 3.750 & 301 & - & - & - \\
\hline Saracá² & 2002 & 823 & 130 & - & - & - \\
\hline Teófilo² & 2005 & 811 & 82 & - & - & - \\
\hline Totais & - & 10.814 & 9.426 & 1.152 & 95 & - \\
\hline
\end{tabular}

Inventário com $100 \%$ de intensidade e somente para castanheira (B. excelsa) com DAP $\geq 10 \mathrm{~cm}$.

2 Inventário amostral para todos os indivíduos com DAP $\geq 10 \mathrm{~cm}$ (limite de erro $\geq 10 \%$ a $95 \%$ probabilidade pelo teste $t$ ).

abundância? Por que no platô Aviso, distante apenas cerca de 10 km do Almeidas e com semelhantes características bióticas e abióticas, foram registrados apenas sete indivíduos com diâmetros variando entre 32,4 cm e 207,5 cm (inventário com 100\% de intensidade) nos 1.365 ha, ou seja, uma abundância praticamente insignificante de 0,005 árvore/ha?

Estas extraordinárias diferenças demográficas entre as populações de castanheira entre os platôs são intrigantes e de difícil explicação. Os fatores naturais que podem favorecer a expansão da população são a ocorrência de clareiras naturais, uma vez que a espécie só se desenvolve após a germinação na presença de luz, e a existência de agentes dispersores de várias espécies e com populações abundantes. Os fatores não naturais seriam aqueles resultantes da ação antrópica, a qual procuraria favorecer o desenvolvimento das populações através do manejo, como, por exemplo, eliminando as espécies competidoras, sobretudo por luz, sendo também resultantes do enriquecimento através do plantio adensado de castanheiras em clareiras naturais e artificiais na floresta.

A possibilidade de eventos raros no passado que tenham favorecido o aparecimento de um grande número de clareiras naturais pode ser descartada através da existência de várias espécies climácicas, características da floresta ombrófila densa, comprovada através do inventário florestal executado por Salomão et al. (2003) no platô Almeidas.

Quanto aos dispersores, a cutia (Dasyprocta aguti L.), um mamífero roedor que ocorre no platô, é a principal responsável pela dispersão das sementes e consequente regeneração da castanheira, uma vez que ela enterra algumas amêndoas (sementes) na floresta. Existem relatos de algumas espécies de macacos (cairara e prego) que se alimentam da castanha, podendo, dessa forma, atuar também como dispersores da espécie (Shanley \& Medina, 2005).

Equipes de arqueologia do Museu Parense Emílio Goeldi, lideradas por Vera Guapindaia e Daniel Lopes, executaram levantamentos arqueológicos na área de interflúvio, próximo a estes platôs, que resultaram na localização de dez novos sítios arqueológicos, ressaltando-se que na margem do rio Trombetas trabalharam em alguns dos sítios localizados por Hilbert (1955, 1988) e Hilbert \& Hilbert (1980). Os vestígios arqueológicos coletados nas escavações compreendem, basicamente, fragmentos cerâmicos líticos, carvões e 
resinas, além de amostras de solos. A análise do material cerâmico quanto aos tipos de decorações, aditivos e formas do vasilhame apresenta características da cerâmica Konduri, conforme descrita por Hilbert \& Hilbert (1980) em sítios ribeirinhos ao rio Trombetas e seu afluente Pocó. Os sítios ribeirinhos, em geral, estão localizados nas margens dos lagos e rios imediatamente acima do nível das águas, constituindo-se em extensas manchas de terra preta contínuas. Estes autores concluem, ainda que preliminarmente, considerando o tamanho, quantidade de material e coloração do solo, que os sítios ribeirinhos foram aldeias maiores e de ocupação permanente. $\mathrm{Na}$ região de interflúvio, entretanto, parece ter havido tanto sítios de ocupação permanente, ainda que de dimensões menores que os da área ribeirinha, quanto sítios de curta duração, semelhantes a acampamentos sazonais.

Estudos específicos que demonstrem se houve manejo das populações de castanheiras pelos ameríndios devem ser desenvolvidos para que se possa, talvez, esclarecer as diferenças demográficas entre as populações dos platôs.

\section{CONCLUSÃO}

A abundância de castanheiras pode ser extremamente baixa (0,25 árvore/ha), quando estimada através de inventário amostral, ou seja, quando uma fração da área total é amostrada, gerando estimativas para toda a população; ou alta (12 árvores/ha), quando a intensidade amostral for de 100\%.

Entre os platôs analisados, conclui-se que no platô Almeidas foi observada uma alta concentração de praticamente 1,5 árvore/ha, completamente oposta à registrada em outro local (platô Aviso) de semelhantes características e abundância 294 vezes inferior àquela.

As populações de castanheiras no platô Almeidas apresentaram a maioria de seus indivíduos na faixa de 100-150 cm de diâmetro, enquanto os indivíduos jovens foram raros; nove excepcionais espécimes apresentaram diâmetros superiores a $300 \mathrm{~cm}$.

A relação entre o diâmetro e a altura total das árvores demonstrou que praticamente todos os indivíduos, independentemente do tamanho do diâmetro, ficam na mesma faixa de altura.

A castanheira apresentou distribuição espacial agrupada no platô Almeidas e aleatória (não agrupada) no platô Aviso.

Projetando-se o incremento do crescimento diamétrico de $0,53 \mathrm{~cm}^{*} a \mathrm{no}^{-1}$ para as árvores que apresentaram diâmetros superiores a $300 \mathrm{~cm}$, conclui-se que essas castanheiras teriam idades superiores a 570 anos, sendo, provavelmente, anteriores aos colonizadores portugueses que chegaram ao Brasil no ano de 1500.

Em síntese, a análise da estrutura das populações do platô Almeidas permite inferir que a árvore média de castanheira (árvore teórica) apresentaria 134 cm de DAP, altura total de 32,3 m, área seccional de 1,6 $\mathrm{m}^{2}$, volume de madeira do tronco de 22,3 $\mathrm{m}^{3}$; biomassa aérea de 18,4 toneladas (peso seco) e uma idade média projetada de 253 anos.

A densidade de castanheiras no platô Almeidas e Aviso é uma questão intrigante e difícil de desvendar. Existe a possibilidade de se considerar a origem antrópica dos castanhais do platô Almeidas, que poderá ou não ser confirmada através de futuros estudos.

\section{AGRADECIMENTOS}

À Mineração Rio do Norte, financiadora deste estudo, ao Instituto Chico Mende de Biodiversidade - ICMBio e seus funcionários na Floresta Nacional Saracá-Taquera, aos colegas do Museu Paraense Emílio Goeldi, William L. Overal, Leandro V. Ferreira, Kácio A. C. Morais, Vitor G. de Freitas, Carlos S. Rosário, Carlos A. S. Silva e Mário R. Santos, e aos revisores deste trabalho, expresso meus sinceros agradecimentos.

\section{REFERÊNCIAS}

ABSY, M. L., G. T. PRANCE \& E. M. BARBOSA, 1986/87. Inventário florístico de floresta natural na área da estrada Cuiabá-Porto Velho (BR-364). Acta Amazonica 16/17: 85-121.

ALLEGRETTI, M. H., 1994. O Destino da Floresta: Reservas Extrativistas e o Desenvolvimento Sustentável na Amazônia: 17-47. Ed. Relume-Dumará, Rio de Janeiro.

ALMEIDA, C. P., 1966. Castanha-do-Pará: sua exportação e importância na economia amazônica. Estudos Brasileiros 19: 1-86. 
BENTES, R. S., R. A. MARIN \& M. F. EMMI, 1988. Os cemitérios das castanheiras do Tocantins. Pará Desenvolvimento (23): 18-23.

BROWN, S., A. J. R. GILLESPIE \& A. LUGO, 1989. Biomass estimation methods for tropical forests with applications to forest inventory data. Forest Science 35(4): 881-902.

CAMARGO, P. B., R. P. SALOMÃO, S. TRUMBORE \& L. A. MARTINELLI, 1994. How old are the brazil-nut trees (Bertholletia excelsa) in the Amazon. Scientia Agricola 51(2): 389-391.

CAMPBELL, D. G., D. C. DALY, G. T. PRANCE \& U. M. MACIEL, 1986. Quantitative ecological inventory of terra firme and várzea tropical forest on the Rio Xingu, brasilian Amazon. Brittonia 38(4): 369-393

CARVALHO, J. O. P., 1981. Distribuição diamétrica de espécies comerciais e potenciais em floresta tropical úmida natural na Amazônia. Boletim de Pesquisa 23: 1-34.

CHAMBERS, J. Q., N. HIGUCHI \& J. P. SCHIMEL, 1998. Ancient trees in Amazonia. Nature 391: 135-136.

CLAY, J. W., 1997. Implications for Biodiversity and Conservation. In: C. H. FREESE (Ed.): Harvesting Wild Species: 246-282. Ed. John Hopkins University Press, Baltimore and London.

DANTAS, M. \& N. R. M. MULLER, 1980. Estudos fito-ecológicos do trópico úmido brasileiro I - Aspectos fitossociológicos de mata de terra roxa na região de Altamira. Anais do $30^{\circ}$ Congresso Nacional de Botânica: 205-218.

DUCKE, A. \& G. A. BLACK, 1954. Notas sobre a fitogeografia da Amazônia brasileira. Boletim Técnico do Instituto Agronômico do Norte 29: 1-48.

HILBERT, P. P., 1955. A cerâmica arqueológica da região de Oriximiná. Instituto de Antropologia e Etnologia do Pará (Publicação do Instituto de Antropologia e Etnologia do Pará, n. 9), Belém.

HILBERT, K., 1988. Relatório de viagem do Projeto de Salvamento Arqueológico na região de Porto Trombetas (PA). III Relatório. Museu Paraense Emílio Goeldi, Belém.

HILBERT, P. P. \& K. HILBERT, 1980. Resultados preliminares da pesquisa arqueológica nos rios Nhamundá e Trombetas, Baixo Amazonas. Boletim do Museu Paraense Emílio Goeldi, Nova Série, Antropologia (75): 25-42.

IBGE, 2005. Produção da Extração Vegetal e da Silvicultura. Disponível em: <http://www.ibge.gov.br>. Acesso em: 10 maio 2007

INEMET, 2006. Instituto Nacional de Meteorologia. Disponível em: <http://www.inemet.gov.br>. Acesso em: agosto 2006.
KITAMURA, P. C. \& C. H. MULLER, 1984. Castanhais nativos de Marabá-PA: fatores de depreciação e bases para sua preservação. Documentos EMBRAPA/CPATU 30: 1-32.

LAPA, R. P., 2000. A bauxita e o rejeito da bauxita. In: R. L. BOZELLI, F. A. ESTEVES \& F. ROLAND (Eds.): Lago Batata: Impacto e Recuperação de um Ecossistema Amazônico: 27-35. IB-UFRJ/SBL, Rio de Janeiro.

MORITZ, A., 1984. Estudos biológicos da floração e frutificação da castanha-do-Brasil. Documentos EMBRAPA/CPATU 29: 1-78.

MULLER, C. H., L. A. RODRIGUES, A. A. MULLER \& N. R. M. MULLER, 1980. Castanha-do-Brasil - Resultados de Pesquisas. Miscelânea 2: 1-25.

PANDOLFO, C., 1960. Castanha-do-Pará e seu beneficiamento: estudo genérico: 1-17. Superintendência do Desenvolvimento da Amazônia - Sudam, Belém.

PAYANDEH, B., 1970. Comparison of methods for assessing spacial distribution of trees. Forest Science 16(3): 312-317.

PEREIRA, I. C. V. \& S. L. L. COSTA, 1981. Bibliografia de castanhado-Brasil (Bertholletia excelsa H. B. K.): 1-192. EMBRAPA/ CPATU, Belém

PERES, C., A. BAIDER, C. ZUIDEMA, A. PIETER, L. H. O WADT, K. A. KAINER, D. A. P. G. SILVA, R. P. SALOMÃO, L. L. SIMÕES, E. R. N. FRANCIOSI, F. C. VALVERDE, R. GRIBEL, G. H. SHEPARD IR., M. KANASHIRO, P. COVENTRY, D. W. YU, A. R. WATKINSON \& R. P. FRECKLETON, 2003. Demographic threats to the sustainability of Brazil nut exploitation. Science 302: 2112-2114

PETERS, C. M., 1994. Sustainable Harvest of Non-timber Plant Resources in Tropical Moist Forest: An Ecological Primer: 1-45. Biodiversity Support Program, Washington.

PIRES, J. M., 1973. Tipos de vegetação da Amazônia. Publicações Avulsas do Museu Paraense Emílio Goeldi 20: 179-202.

PIRES, J. M., 1976. Aspectos ecológicos da floresta amazônica. Anais do $2^{\circ}$ Congresso Brasileiro de Florestas Tropicais. 65: 235-287.

PROJETO RADAM, 1974a. Folha SB22 Araguaia e parte da Folha SC22 Tocantins. Rio de Janeiro. MME/DNPM 4: IV/3-IV/119.

PROJETO RADAM, 1974b. Folha SA22. Rio de Janeiro. MME/ DNPM 5: IV/3-IV/93.

PROJETO RADAM, 1975. Folha SB21 Tapajós. Rio de Janeiro. MME/DNPM 7: 287-384.

PROJETO RADAM, 1976. Folha SA21 Santarém. Rio de Janeiro. MME/DNPM 10: 309-414. 
QUEIROZ, W. T. \& A. V. BARROS, 1998. Inventário floresta de 3.097 ha da Floresta Nacional de Saracá-Tacuera - Município de Oriximiná - Pará: 22-23. Mineração Rio do Norte, Faculdade de Ciências Agrárias do Pará, Belém.

SALOMÃO, R. P., 1991. Estrutura e densidade de Bertholletia excelsa H. \& B. ("castanheira") nas regiões de Carajás e Marabá, Estado do Pará. Boletim do Museu Paraense Emílio Goeldi, série Botânica 7(1): 47-68.

SALOMÃO, R. P., A. H. MATOS, N. A. ROSA, C. S. ROSÁRIO \& M. R. SANTOS, 2003. Inventário florestal em 407 hectares de floresta ombrófila densa, platô Almeidas, da Floresta Nacional Saracá-Taquera/lbama, Porto Trombetas, município de Oriximiná, estado do Pará: 1-259. Relatório Técnico. Ibama, MRN, Belém.

SALOMÃO, R. P., N. A. ROSA, A. F. CASTILHO \& K. A. C. MORAIS, 2006. Castanheira-do-brasil recuperando áreas degradadas e provendo alimento e renda para as comunidades da Amazônia setentrional. Boletim do Museu Paraense Emílio Goeldi. Ciências Naturais 2(1): 65-78.
SHANLEY, P. \& G. MEDINA, 2005. Frutíferas e plantas úteis na vida amazônica: 61-73. CIFOR, Imazon, Belém.

SILVA, M. F. F., N. A. ROSA \& J. OLIVEIRA, 1987. Estudos botânicos na área do Projeto Ferro Carajás. 5 - Aspectos florísticos da mata do Rio Gelado, Pará. Boletim do Museu Paraense Emílio Goeldi, série Botânica 3(1): 1-20.

SUDAM, 1974. Levantamentos florestais realizados pela Missão FAO na Amazônia: 1: 1-397. Relatório Técnico da Superintendência do Desenvolvimento da Amazônia, Belém.

TUPIASSU, A. \& N. V. S. OLIVEIRA, 1967. A castanha-do-pará: Estudos preliminares. Cadernos Paraenses 3: 1-39.

ZUIDEMA, P. A. \& R. G. A. BOOT, 2002. Ecology and Management of the Brazil Nut Tree (Bertholletia excelsa): 1-111. PROMAB (PROMAB Scientific Series 6), Utrecht.

Recebido: 01/09/2008 Aprovado: 09/04/2009 
